\title{
Em destaque: a nova gestão escolar
}

\section{Highlighted: the new school management Aspectos destacados: la nueva gestión escolar}

QUÊNIA RENEE STRASBURG

https://orcid.org/0000-0001-8448-1785

Universidade do Vale do Rio dos Sinos

Programa de Pós-graduação em Educação

Departamento de Educação

São Leopoldo, RS, Brasil

BERENICE CORSETTI

https://orcid.org/0000-0002-4457-8790

Universidade do Vale do Rio dos Sinos

Programa de Pós-graduação em Educação

Departamento de Educação

Porto Alegre, RS, Brasil

Resumo: Neste artigo abordamos a gestão escolar, que é mobilizada como fundante para a qualidade da educação. Cotejando documentos do Banco Mundial e reportagens das revistas Nova Escola e Gestão Escolar 2008-2017, analisamos a articulação de discursos convergentes. O ciclo de políticas (serve como modelo teórico-metodológico que sustenta a análise de políticas como discurso. As revistas compõem uma amostra de como ocorre a receptividade e aceitação às ideias e conceitos de cunho neoliberal e gerencialista na educação.

Palavras-chave: Política educacional. Banco Mundial. Mídia impressa. Gestão escolar.

Abstract: In this article, we address school management, which is understood as a foundation for the quality of education. Comparing documents from the World Bank (WB) and reports from the journals Nova Escola and Gestão Escolar 2008-2017, we analyze the junction of convergent discourses. The Policy Cycle serves as a theoretical-methodological model that supports policy analysis as a discourse. The journals display a sample of how receptivity and acceptance of neoliberal and managerial ideas and concepts in education occur.

Keywords: Educational policy. World Bank. Print media. School management.

Resumen: En este articulo abordamos la gestión escolar, que es movilizada como fundacional para la calidad de la educación. Cotejando documentos del Banco Mundial (BM) y reportajes de las revistas Nova Escola y Gestão Escolar 2008-2017, analizamos la articulación de discursos convergentes. El ciclo de Políticas sirve como modelo teórico-metodológico que sostiene el análisis de políticas como discurso. Las revistas componen una amuestra de como ocurre la receptividad y la aceptación de las ideas y conceptos de carácter neoliberal y gerencialista en la educación.

Palabras clave: Politica educacional. Banco Mundial. Media impresa. Gestión escolar. 


\section{CONTEXTUALIZAÇÕES INICIAIS}

Há um discurso corrente na área educacional, que se origina da área da administração, e da Nova Gestão Pública, de que a gestão escolar é o âmago para a melhoria da qualidade da educação. O crescimento de cursos de gestão, a disseminação de boas práticas de gestão escolar, premiação para gestores, revistas com esse viés específico, além de orientações para tornar a gestão de instituições públicas em privadas, posiciona a gestão escolar como campo de estudos em crescimento. Para compreender como se constituiu e ganhou corpo essa prerrogativa da gestão escolar como elemento chave para garantia de qualidade, propomos conhecer suas bases de sustentação e manutenção.

A partir dos anos 1990, logo após as lutas pela redemocratização no Brasil, o país recebe uma série de influências do contexto externo, e observamos, na política interna, forte presença de organismos internacionais (OI) e do Banco Mundial (BM), a partir da presidência de Fernando Henrique Cardoso. As propostas e orientações desses organismos ocorrem de variadas maneiras, sendo uma delas por documentos orientadores para educação. Constatamos que não há uma proposta unificada dessas organizações, porém, algumas tendências comuns são verificadas, no que diz respeito à gestão escolar. Havia, naquela década, um argumento de que o Estado precisava ser reformado e alterado, no que tratava de suas responsabilidades e competências. Verificava-se uma onda privatista de empresas e terceirização de serviços, até então executados prioritariamente pelo Estado.

A educação permanece como atividade essencial e de direito público subjetivo por lei, porém esse espirito de mudanças também será percebido e propagado para o setor. Uma das formas de interferência e direcionamento ocorre através do pensamento gerencialista, por meio das teorias de gestão. Expressões como performatividade, flexibilidade, eficiência, eficácia, qualidade total, prestação de contas, responsabilização, bônus, avaliações externas, provas para professores, gestão por resultados, gerência, entre outras, passam progressivamente a fazer parte do vocabulário educacional da mudança. O objetivo da proposta de mudança é tornar os serviços mais ágeis, fáceis, eficientes e qualificados. 
Nas décadas seguintes, a educação e a gestão escolar continuam a ser permeadas por esse pensamento, que passa a ser dominante, advindo do neoliberalismo e do gerencialismo ${ }^{1}$. No Brasil, mesmo sob os governos do Partido dos Trabalhadores (PT) durante quase quatro mandatos, e com a garantia de avanços no setor, como a ampliação do acesso à educação, políticas de quotas raciais e sociais, entre outros aspectos, as tendências advindas do contexto externo, foram, em sua maior parte, implementadas como políticas.

Dessa forma, neste trabalho observamos como a gestão escolar é retratada, divulgada e posicionada em reportagens da mídia impressa, nas revistas Nova Escola (NE) e Gestão Escolar (GE), entre 2008 a 2017, cotejando esse material com orientações do BM.

No contexto interno dos países, um meio de divulgar e mobilizar a sociedade para a construção da qualidade da educação é a mídia. Esta ocupa grande espaço de divulgação de ideias e de opiniões no século XXI, em múltiplos formatos: revistas, jornais, televisão, internet, cinema, outdoors, podcast, etc. Para a jornalista Marisa Sanematsu, a mídia informativa é um importante espaço de poder, debate e mediações de conflitos. "Em outras palavras, a mídia tem o poder de selecionar e hierarquizar temas, definindo prioridades." (VIEIRA, 2010, s.p.). Nessa perspectiva, analisamos como as orientações do BM, por meio dos seus documentos para educação e para as políticas para professores, são abordadas nas pautas da mídia impressa, tendo como objeto de análise empírica as revistas NE e GE, tomando como recorte, neste artigo, a gestão escolar.

A opção pela análise empírica dessas revistas ocorreu por estarem entre as revistas educacionais mais vendidas para o público docente. Consequentemente, ambas são formadoras de opinião para um significativo grupo de profissionais da educação, sendo, às vezes, referências pedagógicas e de gestão, exclusivas em muitos municípios e estados do país. Segundo os dados da Associação Nacional de Editores de Revistas (Aner), desde 2007, a NE é a revista brasileira de maior circulação entre o público docente, o que sugere o crescimento do mercado editorial nesse segmento, bem como o aumento de professores no mercado de trabalho e o investimento de setores públicos e privados nesse tipo de material.

\footnotetext{
1 O gerencialismo é a forma de gestão alinhada ao neoliberalismo, e por isso está sempre associado a essa teoria econômica. O gerencialismo teve sua origem sob os governos de Margaret Tatcher (1979-1992) e John Major (1992-1997) e, posteriormente, foi introduzido também nos EUA e na Nova Zelândia. A lógica gerencial traduz no seu cerne o modelo de negócios do setor privado para o setor público. Esta lógica se sustenta com base na crítica ao modelo burocrático por ser difícil de gerir, pouco produtivo e repressivo para o espírito empreendedor. A crença é que o sucesso competitivo deve ser alcançado pela restrição dos sistemas de controle, dando liberdade para que as pessoas possam produzir livremente com excelência. Dessa maneira, gerentes tornam-se líderes que promovem visão e inspiração. Segundo Ball (2011), essa máxima atinge principalmente os diretores de escola, produzindo uma mudança de valores e subjetividades.
}

1010 Rev. Bras. Polít. Adm. Educ. - v. 37, n. 2, p. 1008 - 1031, mai./ago. 2021 
Nesse sentido, nosso entendimento de política não é exclusivamente aquela que se refere aos textos legislativos. As políticas em educação, de acordo com o ciclo de políticas (BALL; BOWE, 1992), utilizado aqui como ferramenta teórico-metodológica, nos auxilia a pensar nos vários contextos que permeiam a elaboração, execução e implementação de políticas. Assim, o BM e a mídia impressa são compreendidos não como os únicos influenciadores das políticas, mas como importantes referências no estabelecimento de orientações e consensos para a área em esfera nacional.

Um dos aspectos desenvolvidos na análise de políticas é a distinção entre política como texto e a política como discurso (BALL, 1993). A política como texto tem base na teoria literária e trabalha com a ideia de representações sobre o texto por meio de codificações complexas. Assim, o texto terá uma pluralidade de conceitos, tantos quantos forem seus leitores.

Os textos são produtos de múltiplas influências e agendas e sua formulação envolve intenções e negociação dentro do Estado e dentro do processo de formulação da política. Nesse processo, apenas algumas influências e agendas são reconhecidas como legítimas e apenas algumas vozes são ouvidas. (MAINARDES, 2006, p. 53).

A política como discurso parte do princípio de que os discursos possuem significados, palavras, frases, em que certas estruturas ou intenções de pensamentos são construídas. Em vista disso, Ball (1993) argumenta, com base em Foucault, que a política como discurso tem o objetivo de distribuir vozes e estabelecer o que é permitido pensar, criando regime de verdades. "Os discursos não são sobre objetos; eles não identificam os objetos, eles os constituem e, na prática de fazê-lo, ocultam sua própria invenção." (FOUCAULT, 1977, p. 49).

Essa perspectiva é importante para compreender o que é política, como ela pode ser pesquisada, e de que maneira "exercem poder por meio de produção de verdade e conhecimento como discursos" (BALL 1993, p. 14). Assim, o discurso determina o que pode ser dito e quem pode dizê-lo, indicando quem tem legitimidade e autoridade na proposição de políticas. 
Mas o discurso é "irredutível à linguagem e à fala" (1974, p. 49). É mais do que isso. Não falamos um discurso, ele nos fala. Somos as subjetividades, as vozes, os saberes, as relações de poder que um discurso constrói e permite. Não "sabemos" o que dizemos, nós "somos" o que dizemos e fazemos. Nestes termos, somos falados por políticas, assumimos as posições construídas para nós dentro das políticas. Trata-se de um sistema de práticas (marketing de seus cursos, promoção de sua instituição) e um conjunto de valores e de ética [...]. ${ }^{2}$ (BALL, 1993, p. 14, tradução nossa).

O discurso constitui e é constituído pelos aspectos que estão além do que visível e do que é perceptível, adentrando a subjetividade que atravessa os sujeitos. Dessa forma, restam poucas maneiras de se livrar ou resistir ao discurso, que acaba criando pontos de diagrama de poder, no qual o próprio Estado acaba sendo também o produto do discurso. Essas questões têm ação, principalmente, sobre os efeitos da política e como os sujeitos e atores conseguem resistir ou alterar o contexto da prática em que realizam as suas atividades cotidianas.

Com o objetivo de compreender essa relação complexa entre política como texto e política como discurso, Ball (2015) retorna à Foucault e aos seus estudos a respeito de como a cultura, a subjetividade e os objetos do conhecimento se constituem numa interação dinâmica e contingente entre discurso e prática social.

Foucault estava interessado tanto nas formas como os discursos são construídos quanto na forma como eles mudam, mas também como eles moldam a existência cotidiana, ou seja, em parte pelo menos, como eles "formam os objetos de que falam" (Foucault, 1974, p. 49). O discurso e as relações de poder concomitantes são manifestas em formas materiais e antropológicas, isto é, em objetos políticos (artefatos, como os chamamos no livro), arquiteturas, subjetividades e práticas. Estes são os "instrumentos e efeitos" do discurso. Nesta medida, não fazemos política, a política nos faz. ${ }^{3}$ (BALL, 2015, p. 2, tradução nossa).

Dessa forma, os discursos sobre política em educação e os artefatos como revistas são importantes na constituição subjetiva de gestores e professores. $\mathrm{O}$ trabalho com documentos do BM, associados aos materiais de mídia impressa das

\footnotetext{
"But discourse is "irreducible to language and to speech" (1974 p. 49); it is "more" than that. We do not speak a discourse, it speaks us. We are the subjectivities, the voices, the knowledge, the power relations that a discourse constructs and allows. We do not "know" what we say, we "are" what we say and do. In these terms we are spoken by policies, we take up the positions constructed for us within policies. This is a system of practices (marketing one's courses, promoting one's institution) and a set of values and ethics."

3 "Foucault was interested both in the ways in which discourses are constructed and how they change, but also how they shape everyday existence, that is, in part at least, how they 'form the objects of which they speak.' (Foucault, 1974, p. 49). Discourse and concomitantly power relations are manifest in material and anthropological forms, that is, in policy objects (artefacts as we call them in the book), architectures, subjectivities and practices. These are the 'instruments and effects' of discourse. To this extent, we do not do policy, policy does us."
}

1012 • Rev. Bras. Polít. Adm. Educ. - v. 37, n. 2, p. 1008 - 1031, mai./ago. 2021 
revistas NE e GE embasam a perspectiva de conhecer e compreender a política como discurso para conhecer e registrar os discursos dominantes, discursos esses que terão mais legitimidade que outros.

Portanto, passaremos a discutir como a gestão escolar se constitui área estratégica na disseminação de ideias, conceitos e atitudes fundamentadas em concepções advindas do neoliberalismo, do gerencialismo e da nova gestão pública, propagados pelo $\mathrm{BM}$, nos seus documentos, e por setores empresariais da mídia impressa brasileira, no caso, da Fundação Lemann, proprietária das revistas NE e GE.

\section{O PERFIL DE GESTOR ESCOLAR}

A gestão escolar ganha destaque nas páginas da revista NE e, por se tornar assunto de extrema importância e foco, ganha um segmento próprio, por meio da revista GE, a partir do ano de 2008. Ambas as revistas são editadas pela Associação Nova Escola, que pertence à Fundação Lemann.

A GE, ao ganhar seu próprio segmento editorial, desponta como área de investimento permanente. O gestor escolar passa a ser concebido como um equilibrista, que deve dar conta de muitas tarefas simultaneamente. Deve dominar as questões administrativas, ser líder, conhecer as políticas públicas, estimular a presença dos pais e da comunidade na escola, ajudar a formar os professores e funcionários, e tudo isso, com objetivo de que os alunos aprendam, conforme estimula a capa da NE. Dessa forma, o diretor vira um gestor, essa é a chamada da matéria dentro da revista.

Quando o diretor se torna um gestor: A verdadeira missão do líder da escola é conciliar as demandas burocráticas e pedagógicas - para garantir que os alunos progridam. Em que medida as condições sociais definem a escola? Até que ponto a escola pode transformar as condições sociais? As duas perguntas, que trazem perspectivas de ações diversas, costumam vir à tona quando se reflete sobre o papel da Educação na sociedade. E dar conta desse compromisso - ou, ao menos, tentar - sempre foi o grande desafio das escolas, embora, muitas vezes, as mazelas sociais funcionem como uma justificativa quando professores e diretores falham em suas tarefas. (NE, n. 01, ago. 2008) ${ }^{4}$.

O diretor, nesta abordagem, tem como missão superar todas as mazelas sociais e evitar que ele mesmo e os professores usem justificativas como essas para as suas falhas. Assim, a questão social e as dificuldades reais dos contextos

As reportagens trabalhadas e os seus excertos não foram referenciadas com o número da página, tendo em vista que o trabalho empírico foi realizado nos sites das revistas NE e GE. No site, as matérias não trazem numeração e/ou página. Por isso, utilizamos a edição, o nome da revista, o mês e o ano da reportagem. 
econômicos e sociais, bem como todas as faltas de recursos diversos, não podem servir como justificativa para as falhas de diretores e professores. A revista propõe um apagamento de todos os problemas vivenciados nas escolas públicas brasileiras no que tange ao financiamento e constituição histórica da sociedade brasileira. E trata o assunto como se tudo que ocorresse fosse por falha de professores e diretores. Dessa maneira, a NE encaminha a ideia da necessidade de responsabilização desses profissionais.

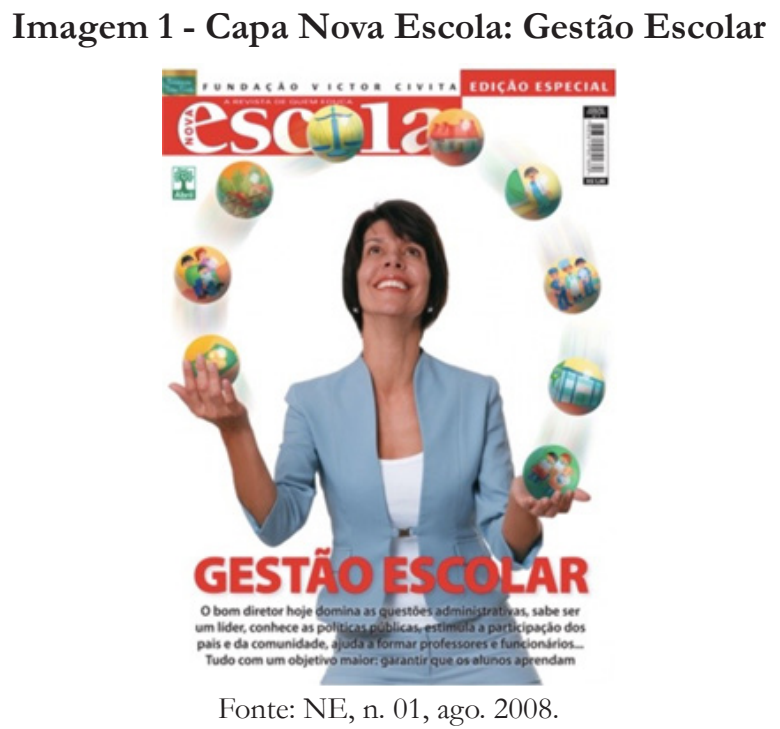

A referência ao diretor que vira gestor (NE, n. 01, ago. 2008) não é mero acaso e tem relação com a ressignificação dada ao termo. A alteração se relaciona com o fato de que o antigo termo diretor não dá mais conta de sustentar as intensas alterações da função, estando desatualizado, passando, por isso mesmo, a ser nomeado gestor. Essa substituição ocorre dentro da mudança nas concepções de administração do Estado, que passam a atuar numa racionalidade gerencialista sobre as diferentes ordens sociais e que chega também à escola. Apesar das reportagens da NE e da GE se referirem com frequência à gestão democrática de acordo com a Lei de Diretrizes e Bases da Educação Nacional, o desenrolar das matérias descreve ações e conceitos gerencialistas. 
Sim, a expectativa em relação à função vem mudando muito nas últimas décadas. Um dos momentos mais importantes dessa transformação ocorreu em meados dos anos 1980, quando a ideia de que o modelo de gestão dos sistemas públicos estava ultrapassado virou um consenso entre os educadores. A solução foi aproximar os serviços governamentais dos princípios da gestão empresarial, nos quais a busca pela eficiência é o maior valor. Desde então, de certa forma, a gestão escolar vem se adaptando para incorporar essa lógica à realidade das salas de aula. (NE, n. 01, ago. 2008, s. p., grifo nosso).

Em outra edição, a GE, através de uma pesquisa da Fundação Vitor Civita com 400 diretores em 13 capitais brasileiras, mostra que os gestores estão mais preocupados com a burocracia do que com melhoria do aprendizado dos estudantes. A revista reforça a concepção de que o perfil de gestor ideal (o gestor gerente) não foi assimilado e conquistado pelos diretores brasileiros.

Em seu cotidiano, as prioridades da agenda são cuidar da infraestrutura, conferir a merenda, vigiar o comportamento dos alunos, atender os pais, receber as crianças na porta, participar de reuniões com as secretarias de Educação e providenciar material. Sobra pouco tempo para conversar com professores, prestar atenção nas aulas e buscar a melhoria do ensino, a meta essencial da escola. (GE, n. 28 , ago. 2009 , s/p, grifo nosso).

Segundo reportagem da GE, o bom gestor é aquele que se preocupa com a aprendizagem dos seus estudantes a partir do acompanhamento e da vigilância dos professores, em consonância com as orientações do BM.

Sistemas educacionais de alto desempenho, tais como os de Cingapura e Ontário (Canadá), prestam muita atenção em como os diretores das escolas são selecionados, treinados e aperfeiçoados, dando ênfase especial à sua habilidade de medir e desenvolver a qualidade dos professores (Schwartz e Mehta 2014; Tucker 2011; Barber e Mourshed 2007). Apesar da crescente conscientização do papel central dos dirigentes, evidências empíricas sobre como melhorar suas habilidades e eficácia são escassas. A maioria dos países da América Latina e do Caribe está apenas começando a desenvolver sistemas de seleção, formação e orientação de dirigentes escolares. (BRUNS; LUQUE, 2014, p. 39, grifo nosso).

A formação dos gestores escolares é bastante enfatizada tanto pela NE como pela GE, porém não é qualquer perspectiva de formação, e sim uma perspectiva específica. A formação defendida é a da nova gestão pública, que é sempre trazida como fundamental para o exercício do cargo. 
Antes de atribuir ao diretor uma alta carga de responsabilidade pelo sucesso da escola, o sistema educacional inglês resolveu investir na preparação desse profissional. De 2002 a 2012, era obrigatório passar por cursos de formação de liderança, aprender com gestores mais experientes e ser avaliado para receber um certificado de aptidão para assumir o cargo. (GESTÃO ESCOLAR, n. 40 , set. 2015, s/p, grifo nosso).

O investimento na formação está ancorado no conceito, advindo da economia da educação, de capital humano ${ }^{5}$, no qual os valores da instrução elevam a capacidade de criar e receber rendimentos. De acordo com Schultz (1967), há três vantagens relacionadas na instrução: (1) consumo atual, (2) consumo futuro (investimento), e (3) capacidade futura do produtor. Sobre os desdobramentos e os valores de cada uma dessas vantagens, não há como saber ao certo. Entretanto, a capacitação dos gestores se constitui uma forma de vantagem mesmo diante dos riscos, no que contempla os três aspectos mencionados.

O gestor é o sujeito que está no foco das reportagens das revistas NE e GE, numa constante busca pela identidade do diretor.

\section{Imagem 2 - Capa Gestão Escolar: Quem é e o que pensa o diretor escolar}

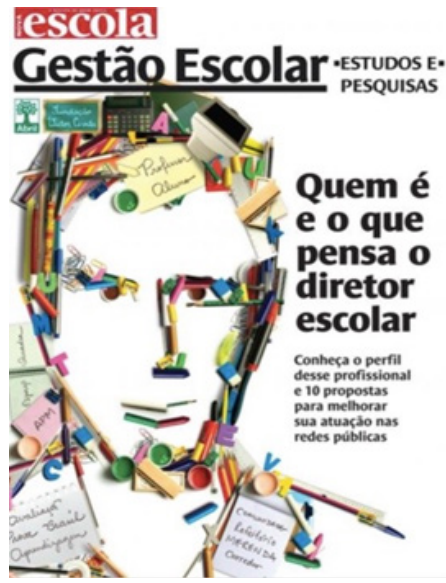

Fonte: GE, n. 28, out. 2009.

Capital Humano como um conceito fechado foi formulado por Theodore Schultz, mas suas bases foram lançadas bem antes disso. A origem estaria em Adam Smith, Alfred Marshall e Irving Fisher. Schultz, na década de 1950, tinha como objetivo compreender o motivo das desigualdades econômicas e sociais entre as nações e grupos de indivíduos no contexto do pós-Segunda Guerra Mundial. A explicação para essas desigualdades foi justificada pela diferença existente no investimento humano. Em seu livro "Valor Econômico da Educação", Theodore Schultz (1967) explica que seu objetivo foi trazer para a educação a colaboração da análise econômica. Desde 1994, pesquisadores alemães elegem anualmente palavras que consideram como não palavra (unwort, em alemão). Segundo os pesquisadores, há palavras que não são adequadas ao termo designado e que, às vezes, até violam a dignidade humana. Em 2004, "capital humano" foi a palavra eleita como não palavra, com a justificativa de que "degrada pessoas a grandezas de interesses meramente econômicos" (ALTVATER, 2010, p. 75). 
O diretor/gestor deve ser o líder da equipe e responsável pelo processo de gerenciamento que leva toda escola à participação, como mostra a chamada do artigo: "Um líder eficiente cria uma cultura de altas expectativas" (GE, n. 40, set. 2015, s/p.). A revista toma como modelo o exemplo de formação dos gestores da Inglaterra, chamada Escola de Líderes.

Essa realidade foi estudada por Maria Carolina Nogueira Dias, consultora em Educação e doutoranda em Políticas Públicas na Fundação Getúlio Vargas (FGV), durante pesquisa realizada pela Fundação Itaú Social em parceria com o British Council. Nesta entrevista, ela explica o contexto de criação de uma escola de líderes e dá indicações de como o Brasil, aproveitando o capital humano que já existe, pode se inspirar na experiência inglesa para qualificar a Educação do país. (GE, n. 40, set. 2015, s/p, grifos nossos).

Nos mesmos moldes da Escola de Líderes, citada na matéria, foi proposta, no documento Pátria Educadora (2015), a criação de Centro de Formação para diretores que seriam ligados ao Instituto Nacional de Estudos e Pesquisas Anísio Teixeira (Inep). Hypolito (2015) registra que ações de formação com características gerencialistas, e numa nova estrutura, já estão em implementação no Brasil, como, por exemplo, em Minas Gerais, onde o governo estadual criou a Magistra - a Escola da Escola. A GE aproxima-se à proposta que o BM tem idealizado em liderança para diretores/gestores, no qual os países em desenvolvimento devem ser orientados para alcançar altas expectativas.

O Chile fornece um bom exemplo de estratégia incremental para aumentar a qualidade dos dirigentes das escolas. Assim como na política de formação de professores, o Ministério da Educação começou pela definição de padrões. O Marco para la Buena Dirección (Padrão para a Boa Direção Escolar), criado em 2004, estabeleceu critérios para a formação e avaliação de dirigentes nas áreas de liderança, gestão de currículos, gestão de recursos e gestão do ambiente organizacional, além de ter estabelecido um processo competitivo para a seleção de diretores (Ministerio de Educación, Chile 2005; Concha Albornoz 2007). Uma lei de 2011 fortaleceu o processo de seleção e aumentou a autonomia e a responsabilidade dos diretores. Os diretores podem demitir até $\mathbf{5 \%}$ dos professores da escola ao ano por desempenho e devem assinar acordos de desempenho com os governos locais que os contratam. O governo também introduziu o Programa de Formación de Directores de Excelencia (Programa de Formação de Diretores de Excelência) em 2011, que forneceu formação de liderança para mais de 1.600 dos 7.000 diretores do país. O programa subsidia taxas e custos de sustento de programas de pós-graduação (mestrado, diplomas, cursos) e de extensão voltados para a direção de escolas. Os programas são selecionados por meio de uma licitação pública: em 2013, os candidatos podiam escolher entre 29 programas de 15 instituições, principalmente no Chile, mas também no Canadá e na Inglaterra. Embora a abordagem do Chile permita diversidade na formação oferecida aos diretores, diversos países da OCDE 
optaram por desenvolver treinamento interno de diretores. O Institute for Teaching and School Leadership (Instituto de Ensino e Direção de Escolas) da Austrália, criado em 2010, desenvolve padrões, credenciamento e formação de professores e diretores de escolas (OCDE 2012). Os diretores também recebem treinamento interno em Cingapura, onde os jovens professores são avaliados quanto ao potencial de liderança já no início da carreira e seguem um acompanhamento especializado de capacidade de liderança. (BRUNS; LUQUE, 2014, p. 39, grifos nossos).

O perfil de diretor como líder de excelência é reforçado nos documentos do BM, que atribui a esse perfil a responsabilidade pelo trabalho e desempenho do professor. A avaliação do diretor será determinante para a renovação ou não de contratos de docentes, como sugerem os exemplos acima. O diretor líder une as capacidades administrativas e pedagógicas, desempenhando ambas de maneira exímia e levando toda a escola para o rumo da excelência.

A busca pela identidade e perfil desse diretor é tema recorrente nas capas e edições da GE, inclusive com um teste para descobrir qual é o seu perfil de gestor.

\section{Imagem 3 - Capa Gestão Escolar: Quem é você? gestão escolar}

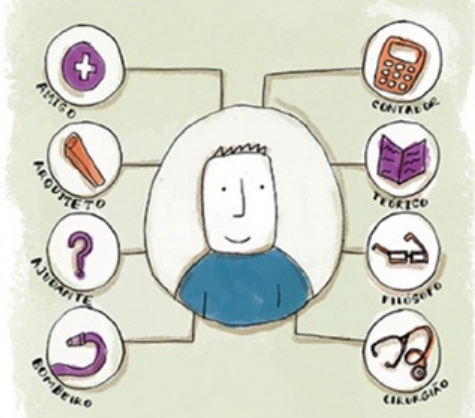

Quem é você?

Testes para descobriri seu perfil de gestor

Fonte: GE, n. 55, mar. 2017.

Nesta edição de março de 2017: O jeito do gestor ideal, novamente, a experiência da Inglaterra aparece como referência para os gestores brasileiros. 
Mesmo em países que há formações e exigências específicas para ser diretor de escola, nem todos têm um mesmo perfil de gestão. Na Inglaterra, os pretendentes ao cargo passam por um programa de quase um ano, entrevista e testes para assumir a posição na escola. Mas pesquisadores do Centre for High Performance, no Reino Unido, investigaram os estilos de liderança escolar comparando ações com resultados no Programa Internacional de Avaliação de Alunos (Pisa, na sigla em inglês) e identificaram a existência de cinco estilos. Apenas um se mostrou eficiente na melhoria do desempenho dos estudantes. (GE, n. 55, mar. 2017, s/p, grifos nossos).

Os cinco estilos identificados pela pesquisa e reproduzidos pela GE são: (1) Cirurgião, que só se preocupa em melhorar os índices das avaliações em larga-escala, e acaba limitando a aprendizagem dos estudantes; (2) Soldado, que direciona suas energias para função administrativa e financeira, deixando o pedagógico para o coordenador; (3) Contador, que sabe lidar muito bem com os números e investe em projetos dos estudantes, mas é preciso lembrar que o investimento precisa reverter em aprendizagem; (4) Filósofo, que é apaixonado pela educação e adora discutir experiências ou metodologias pedagógicas, porém é raro conseguir avanços nas aprendizagens; e (5) Arquiteto, cujas ações provocam positivas e profundas transformações na aprendizagem, pois envolvem a comunidade. O perfil ideal, segundo a GE, é o quinto perfil que deve combinar o que há de melhor nos outros perfis descritos. Podemos perceber que os cinco perfis colocam a aprendizagem como objetivo central a ser alcançado pelo gestor para atingir uma boa educação.

A forma de escolha do diretor foi pauta da edição de $n^{\circ} 45$ da GE, que revelou que eleição é a prática comum nos estados brasileiros para a escolha de diretor, entretanto há pouca clareza quanto aos critérios utilizados.

A eleição direta é o processo mais usado para preencher as vagas de diretor nas redes estaduais de ensino. Ela é a única forma de seleção em seis estados e, em outros dez, aparece combinada com outras metodologias, como certificação e indicação por instâncias locais. Essa última, por sua vez, é a segunda mais comum e aparece sozinha, como modo exclusivo de ascensão ao cargo em quatro unidades da federação.

Contudo, seja qual for a forma de acesso, um fator está presente em todos os estados: não há critérios claros para escolher o gestor da escola - que é, em última instância, quem responde pelo desempenho e pela aprendizagem dos alunos - nem para orientá-lo em seu trabalho. [...]. A iniciativa contou com o apoio do Conselho Nacional de Secretários de Educação (Consed), do Itaú BBA, do Instituto Unibanco, da Fundação Itaú Social e da Fundação SM. (GE, n. 45, mar. 2011, s/p, grifos nossos). 
A escolha do diretor, nos processos acima descritos, é considerada problemática pela revista porque a maior parte dos formatos de escolha não está focada nas competências para o desempenho profissional. As competências fundamentais do diretor incluem o conhecimento pedagógico e a capacidade de gerir pessoas, segundo a reportagem. Para sanar essa lacuna, a GE consulta especialistas que sugerem cinco critérios básicos para as secretarias de educação. Os critérios sugeridos foram: (1) competências de resultados, (2) competências de planejamento, (3) competências de liderança, (4) competências pedagógicas, e (5) competências administrativas. As competências elencadas como fundamentais para uma escolha correta do diretor comprovam que, embora a GE, em determinados momentos, relativize os resultados escolares, os mesmos têm centralidade no trabalho escolar.

Na capa da mesma edição, abaixo, no canto esquerdo, chama atenção a gravura de um quadro verde escrito: "Fundação Vitor Civita", e, ao lado, em caixa alta: "estudos e pesquisas educacionais".

\section{Imagem 4 - Capa Gestão Escolar: Como escolher um bom gestor escolar}

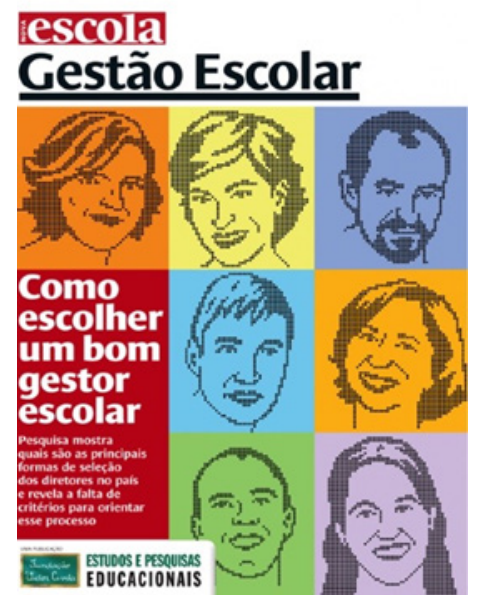

Fonte: GE, n. 45, mar. 2011.

A busca na internet pela "Fundação Vitor Civita: Estudos e Pesquisas Educacionais" foi direcionada ao site da GIFE', no qual encontramos a chamada que a Fundação Vitor Civita lançava o segundo livro: "Estudo e pesquisas educacionais".

\footnotetext{
6 O Grupo de Institutos Fundações e Empresas (GIFE) é uma associação de investidores sociais no Brasil, que podem ser institutos, fundações ou empresas. É uma organização sem fins lucrativos que é referência em investimento social privado do terceiro setor.
} 
O livro reúne artigos acadêmicos dos quatro estudos realizados pela área de Estudos e Pesquisas Educacionais da Fundação Victor Civita em 2010 e será distribuído gratuitamente para universidades dedicadas à formação de professores e institutos de pesquisa em educação. "Com essa iniciativa temos como objetivo disseminar entre pesquisadores, universidades, organizações não-governamentais e institutos de pesquisa, informações relevantes sobre educação no Brasil", diz Angela Dannemann, diretora executiva da Fundação Victor Civita.

Os estudos presentes no livro são: "Mapeamento de Práticas de Seleção e Capacitação de Diretores Escolares", realizado pelo Centro de Desenvolvimento Humano Aplicado (Cedhap) e coordenado pela professora Heloisa Lück; "O Coordenador Pedagógico e a Formação de Professores: Intenções, Tensões e Contradições”, coordenado pela professora Vera M. N. S. Placco e Laurinda R. de Almeida da PUC-SP, e pela professora Vera Lúcia Trevisan de Souza da PUC-Campinas; "Formação Continuada de Professores: Uma Análise das Modalidades e das Práticas em Estados e Municípios Brasileiros", encomendado à Fundação Carlos Chagas; e "A Avaliação Externa como Instrumento de Gestão Educacional nos estados", solicitado ao Grupo de Avaliação e Medidas Educacionais (Game), da UFMG, e coordenado pelo professor Nigel Brooke. (GIFE. 2018, s/p, grifos nossos).

GE e NE, em vários momentos, se utilizam das redes políticas e das sutilezas midiáticas para disseminar suas ideias e concepções para a educação pública brasileira. A Fundação Vitor Civita, para respaldar suas matérias e reportagens, segue o exemplo do BM como produtora e indutora de conhecimento ${ }^{7}$. Para isso, estabelece suas próprias pesquisas como fonte. As temáticas escolhidas são aquelas já amplamente discutidas nas revistas GE e NE, com exceção do coordenador pedagógico, sendo elas: seleção e capacitação de diretores, a formação de professores, formação continuada de professores e avaliação externa como instrumento de gestão.

$\mathrm{Na}$ edição 45 da GE, outra reportagem enfatiza que o critério de escolha do diretor precisa ser profissional e não político. Ao ler a chamada, em princípio, todos concordamos com o mencionado critério. Contudo, no desdobramento do texto, fica evidente que o aspecto profissional está relacionado puramente à competência técnica. Dessa maneira, cria-se a visão de que o gestor adequado e profissional é aquele que se dedica aos aspectos técnicos, deixando as questões políticas de lado. Contudo, não há um aprofundamento sobre cada um desses conceitos, como é comum nas reportagens.

7 Para mais informações sobre o Banco Mundial e suas influências na trajetória das políticas educacionais, ver Strasburg (2019). 


\section{A FORMA DE GESTÃO}

Após a escolha do diretor, as reportagens caminham para a ideia de que a preparação e a formação, para quem está no cargo, deve impedir que este se coloque na posição de professor. Vale lembrar que a LDB 9.394/96 garante a gestão democrática do ensino público ou que deve incluir, pelo menos em tese, a eleição para diretor ou equipe gestora das unidades escolares. Porém, ao assumir o cargo de líder, o gestor não deve mais aderir às questões dos professores, tendo em vista que o $\mathrm{BM}$ acredita que eles tenderão ao corporativismo e a não enxergarão os problemas do seu contexto.

Uma questão relacionada é que, mesmo que as escolas tenham a autoridade e a capacidade de tomar decisões, as escolas e os professores podem não saber como melhorar a qualidade. Os administradores escolares podem ser resistentes à mudança porque não conhecem nenhuma outra maneira de agir. Os professores podem estar relutantes em mudar os métodos de ensino ${ }^{8}$. (BRUNS; FILMER; PATRINOS, 2011, p. 77, tradução nossa).

A orientação do BM é de que a gestão escolar, segundo a School Based Management/ Gestão Baseada na Escola (SBM), deve ser descentralizada. Nessa proposta, a responsabilização das ações e decisões são transferidas para a escola. Assiste-se a uma inversão da gestão democrática, no sentido de que a participação não se constitui num processo de compreensão de que todos os sujeitos podem contribuir para escola. $\mathrm{Na}$ descentralização, a intenção principal parece ser que os conselhos escolares, e/ou outras organizações de gestão, sejam responsáveis pela escola através de ações de monitoramento das avaliações externas, na vigilância aos professores, nas decisões de demissão e principalmente como responsáveis pela sua manutenção financeira.

$8 \quad$ "A related issue is that, even if schools have the authority and the ability to make decisions, schools and teachers may not know how to improve quality. School administrators may be resistant to change because they don't know any other way of acting. Teachers may be reluctant to change teaching methods." 
Um número crescente de países em desenvolvimento está introduzindo reformas de escolas baseadas em gerência (SBM) com o objetivo de fortalecer os diretores e professores ou fortalecer sua motivação profissional, aumentando assim o senso de propriedade da escola. Muitas dessas reformas também fortaleceram o envolvimento dos pais nas escolas, às vezes por meio de conselhos escolares. SBM normalmente trabalha através de um comitê escolar (ou um conselho escolar ou comitê de gestão da escola) que pode $\bullet$ monitorar o desempenho da escola, por exemplo, nos resultados de testes ou na frequência de professores e alunos; • levantar fundos e criar doações para a escola; • nomear, suspender, demitir e remover professores e assegurar que os salários dos professores sejam pagos regularmente; e• aprovar (embora raramente) os orçamentos anuais, incluindo o orçamento de desenvolvimento, e examinar as demonstrações financeiras mensais. ${ }^{9}$ (BRUNS; FILMER; PATRINOS, 2011, p. 88-89, tradução nossa).

\title{
A descentralização da gestão escolar e a chamada a participação da comunidade e dos pais é sustentada conforme o modelo de governança, com consequente responsabilização.
}

\begin{abstract}
SBM é usado para aumentar a autonomia escolar e responsabilidade, o que pode ajudar a resolver alguns dos problemas mais fundamentais nas escolas. Consequentemente, embora seja necessário aumentar os fluxos de recursos e outros apoios ao setor da educação para dar aos pobres um maior acesso a uma educação de qualidade, não é suficiente. Também é necessário traduzir esses recursos em serviços básicos acessíveis aos pobres. Portanto, sob SBM, as escolas são dadas alguma autonomia sobre o uso de seus insumos e são responsáveis por usar esses insumos eficientemente ${ }^{10}$. (BRUNS; FILMER; PATRINOS, 2011, p. 90, tradução nossa).
\end{abstract}

As políticas de descentralização são marcadas pelos princípios do empreendedorismo, que solicita à equipe escolar, pais, estudantes e comunidade, a disposição de se engajarem nos problemas educacionais. Todos devem buscar formas de resolver as dificuldades e mudar o quadro dos resultados do sistema

$9 \quad$ "An increasing number of developing countries are introducing SBM reforms aimed at empowering principals and teachers or strengthening their professional motivation, thereby enhancing their sense of ownership of the school. Many of these reforms have also strengthened parental involvement in the schools, sometimes by means of school councils. SBM usually works through a school committee (or a school council or school management committee) that may - monitor the school's performance in, for instance, test scores or teacher and student attendance; raise funds and create endowments for the school; - appoint, suspend, dismiss, and remove teachers and ensure that teachers' salaries are paid regularly; and-approve (albeit rarely) annual budgets, including the development bud-get, and examine monthly financial statements."

$10 \quad$ "SBM is used to increase school autonomy and accontability, which can belp solve some of the most fundamental problems in schools. Accordingly, while increasing resource flows and other support to the education sector is necessary to give the poor greater acess to quality education, it isby no means sufficient. It's also necessary to translate these resources into basic services that are acessible to the poor. Therefore, under SBM, schools are given some autonomy over the use of their inputs and are held accontable for using these inputs efficiently." 
nacional de avaliação. "As políticas de descentralização têm como foco a gestão e o financiamento da escola pública em um processo crescente de participação e responsabilização." (ANADON; GARCIA, 2015, p. 344).

Muitas reportagens da NE e da GE vão no sentido de conclamar a participação da comunidade com chamadas que incentivam o foco na aprendizagem.

\section{Imagem 5 - Capa Gestão Escolar: Reconstrução Coletiva}

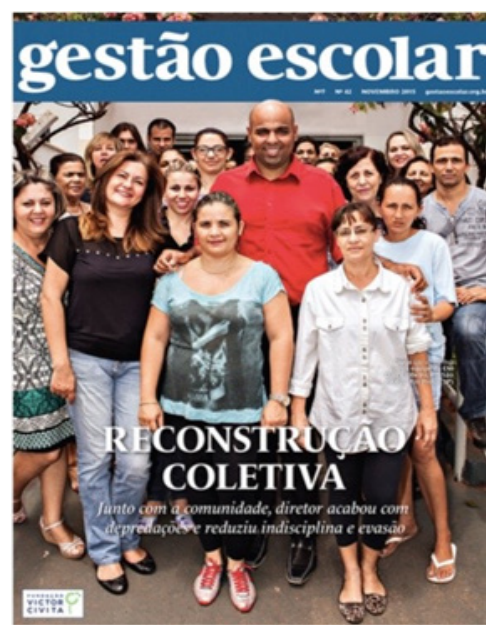

Fonte: GE, n. 28, out. 2009.

A participação da comunidade na escola é apresentada, na edição 28 da GE, a partir de uma experiência ocorrida no interior de São Paulo. A matéria inicia dizendo que o novo diretor, ao chegar à escola, deparou-se com uma cena de filme, com alunos ateando fogo nas lixeiras, jogando restos de merenda contra ele, fazendo manifestações com cartazes. Dois antigos diretores já haviam desistido do cargo e, então, com a ação de diálogo e de ouvir os estudantes que tinham vergonha da sua escola, o diretor conseguiu transformá-los em aliados. Foi o primeiro ato de uma gestão participativa, segundo a GE.

O excerto acima engendra a figura do diretor/gestor como herói, evocando o cenário do cinema que coloca a escola como um lugar completamente esquecido. $\mathrm{E}$ as causas desse esquecimento eram pela falta de um líder, falta essa que foi suprida com a chegada do gestor- herói ou do gestor-salvador. Nessa reportagem, fica em evidência a personificação da figura do diretor como propõe a Nova Gestão Pública. 
Uma gestão performática (baseada no desempenho) e sistemas de prestação de contas e responsabilização (accountability) têm colonizado os sistemas educacionais em todo o mundo. Um processo que pode ser personificado na figura do "gestor" e que está alimentado pelos discursos e práticas do que algumas vezes é denominado Nova Gestão Pública (NGP). (BALL et al, 2013, p. 13, grifo nosso).

A descentralização da gestão caminha ao lado de outras políticas centralizadas. Um desses exemplos é das políticas de avaliação que induzem todo o trabalho escolar. Descentraliza-se a gestão e a responsabilidade sobre a escola pelo Estado e centraliza-se a maneira de regular. As matérias da NE e da GE trabalham com discursos que mesclam ações da SBM com ações realizadas diariamente no cotidiano escolar das escolas públicas brasileiras. Nesse sentido, é difícil articular temáticas tão imbricadas e naturalizadas como a de que cabe ao diretor e aos professores salvar a escola contemporânea.

Contribui com esses princípios e ideias, o Compromisso Todos pela Educação, organização que tem entre seus membros uma ampla gama de empresários brasileiros, que estabelece os meios de comunicação de massa como alvos para divulgar suas premissas fortemente ancoradas nas recomendações das OIs e do BM.

O documento Todos pela Educação: rumo a 2022 tem como alvo primeiro os formadores de opinião. De modo específico, visa atingir os meios de comunicação em massa, considerando que esses possuem um poder persuasivo, sendo instrumentos importantes no desenvolvimento de novas atitudes e consciência social com relação à educação. Conforme expresso na introdução do documento: "terá como público-alvo, primordialmente, os profissionais de comunicação”. (SHIROMA; GARCIA; CAMPOS, 2011, p. 235).

Uma das diretrizes do documento "Compromisso Todos pela Educação: rumo a 2022”, que está organizado em 10 mensagens, é que, na 9ª a gestão do aprendizado é papel do diretor. A mensagem ressalta que o diretor é uma liderança imprescindível para transformar sua escola numa escola eficaz. Dessa maneira, o TPE exerce influência no contexto educacional, provocando um deslocamento da noção de gestão democrática para uma gestão participativa, na qual os agentes são convidados não para partilha de poder, e sim para a partilha das responsabilidades (SHIROMA; GARCIA; CAMPOS, 2011). Educar os clientes para fazer a pressão sobre o trabalho da escola através do diretor/gestor escolar é a tônica das matérias aqui selecionadas.

Diego é o diretor-herói da edição 28 da GE, e os professores são os sujeitos que precisam de uma liderança que os motive ao trabalho, já que são retratados como resistentes às mudanças. $\mathrm{O}$ problema não eram os alunos que 
rapidamente se convenceram das propostas e intenções do diretor-herói, nem a comunidade tampouco foi problema, os únicos resistentes, contudo, foram os professores.

Existem poucas evidências de pesquisas até o momento sobre qualquer dessas estratégias, exceto a capacitação dos clientes: formas "fortes" de gestão baseada na escola, nas quais os pais e membros da comunidade tinham uma participação na contratação e demissão do pessoal da escola e receberam treinamento e incentivos para exercer esse poder, mostraram em alguns contextos que podiam reduzir as faltas dos professores e aumentar os resultados da aprendizagem dos alunos. (BRUNS; LUQUE, 2014, p. 42, grifos nossos).

A sugestão de utilização das instâncias de gestão democrática para funções de responsabilização, conforme a proposta elaborada pelo BM, cria uma inversão quanto à função dessas instâncias. De um lado estão o diretor, os estudantes, os pais e a comunidade, e do outro, os professores. Cabe lembrar que o diretor também está inserido no pacote da avaliação e da pressão externa, porém se ele cumprir os passos traçados com exatidão e fizer a pressão necessária sobre os professores, distanciando-se deles e mobilizando todos os recursos possíveis na comunidade, ele está a salvo.

A celebração da gestão ou "funções diretivas" nas escolas, como oposição aos docentes, é uma parte muito simbólica desse processo. "Funções diretivas" são crescentemente fortalecidas com um número maior de responsabilidades, com formas variadas, que podem ser vistas como figuras-chave nas reformas neoliberais e na "modernização" do setor público. Elas "[...] desempenham uma função-chave no desgaste dos regimes ético-profissionais nas escolas e na sua substituição pelos regimes empresariais-competitivos - um processo de “desprofissionalização" [docente].” (BALL, 2008 apud BALL et al, 2013, p. 14).

O foco no diretor é proposital e auxilia na desprofissionalização dos professores, que acabam sendo colocados como resistentes, preguiçosos e largados. A reorganização da função do diretor como líder nas questões administrativas e pedagógicas, estrategicamente abre a possibilidade para que o diretor observe e cobre o trabalho do professor, na perspectiva da responsabilização. 
Em termos de supervisão gerencial, o papel dos diretores de escola na gestão do desempenho dos professores na América Latina e no Caribe tem sido geralmente fraco. Uma pesquisa realizada nos Estados Unidos documentou que muitos líderes em educação na América Latina e no Caribe observam: escolas de elevado desempenho alcançam o sucesso por meio de uma gestão qualificada do corpo docente. Os diretores dessas escolas atraem bons professores, demitem professores ineficazes e empregam e desenvolvem novos professores de modo mais eficaz do que os diretores de outras escolas. Diretores eficazes têm a capacidade de observar professores na sala de aula, fornecer-lhes um feedback formativo e gerenciar sua "saída" da escola, se necessário. Diretores eficazes apoiam o desenvolvimento dos professores e exigem deles a responsabilidade pelo desempenho (Branch, Hanushek e Rivkin 2013; Boyd et al. 2008; Loeb, Kalogrides e Béteille 2012). (BRUNS; LUQUE, 2014, p. 42-43, grifos nossos).

Dessa maneira, uma das tarefas do diretor/gestor destacada pelos documentos do BM está no monitoramento dos professores como maneira de melhoria da aprendizagem.

O diretor, como registra a GE, é um dos fatores que mais impacta a aprendizagem dos estudantes, atrás apenas da qualidade dos professores e, por isso, o diretor precisa ser treinado como o líder de uma empresa, claro que dentro das especificidades da educação, enfatiza a GE.

\section{CONSIDERAÇÕES FINAIS}

Neste artigo, procuramos dar visibilidade às aproximações discursivas entre os documentos orientadores do $\mathrm{BM}$ para América Latina e Caribe às reportagens veiculadas nas revistas Nova Escola e Gestão Escolar acerca da gestão na escola. Ficou evidente a convergência entre documentos e as temáticas/ assuntos abordados nas revistas, de maneira que até os exemplos de políticas utilizados nas reportagens são os mesmos citados nos documentos para serem seguidos nos países em desenvolvimento.

A gestão escolar ganha destaque nas páginas da revista Nova Escola, e, por se tornar assunto de extrema importância e foco, ganha um segmento próprio, por meio da revista Gestão Escolar, a partir do ano de 2008. Merece destaque o formato das matérias, que mesclam frases ou opiniões rápidas ou sucintas de pesquisadores de referência das áreas. Porém, não é possível compreender se os pesquisadores foram consultados ou se suas frases foram simplesmente jogadas dentro das matérias. Essa dinâmica é quase um padrão das revistas. As reportagens também mesclam pesquisadores de setores públicos, privados, terceiro setor, apresentados a todos como especialistas na área. A Associação Nova Escola, por meio da sua equipe técnica, comprova sua organização como 
revista jornalística com cunho pedagógico. Porém, as revistas quase não têm professores ou pesquisadores em educação na sua diretoria executiva. A maior parte da equipe tem ou teve relação com a Fundação Lemann e alguma experiência em universidades estrangeiras.

A estrutura organizacional da Associação Nova Escola segue a dinâmica de que não precisa ser da área educacional para tratar de educação ou editar uma revista de cunho pedagógico educacional. Nesse sentido, é reforçado o pensamento comum de que administradores, economistas, consultores em marketing, designers e demais profissionais têm mais a dizer sobre educação do que os próprios especialistas na área educacional. Assim, a problemática que levantamos é que as orientações para gestão da escola, realizada por meio da mídia impressa, no caso das revistas analisadas, tem um direcionamento claro e são filiados a uma determinada visão de gestão, de professores, de escola, entre outros, que são encobertas com um tom de neutralidade e imparcialidade.

A gestão escolar ou a nova gestão escolar anunciada, na perspectiva neoliberal-gerencialista, passa a ter um papel de destaque através do discurso de garantia de qualidade, liderança e eficiência. $\mathrm{O}$ modelo de gestão escolar e liderança apregoado tem como fundamento o modelo das instituições privadas e de países que utilizam responsabilização de diretores e professores para aumentar os resultados educacionais, conforme os documentos do BM, com ressonâncias em GE e NE. Para execução do seu papel, o gestor na escola é reivindicado a constituir um modelo de governança, como uma nova maneira de participação da comunidade. A comunidade passa a ser compreendida como cliente e a educação como mais um dos bens de consumo.

O destaque à gestão escolar estabelece tanto a forma de atuação como um novo direcionamento à carreira docente, no sentido de incentivar os professores a ascenderem como líderes individuais, ao invés de desenvolverem capacidades profissionais docentes. O gestor, quando assume sua nova função, precisa esquecer seu fazer docente, passando a regular o trabalho do professor. O gestor ideal é o gestor herói que resolve todos os problemas das comunidades desiguais. A gestão é a responsável por dar um rumo ao trabalho escolar e, assim, cada escola precisa ter uma gestão forte, como forma não apenas de organizar e liderar o trabalho, mas de realizar a avaliação e a pressão constante sob os professores, com o apoio da comunidade.

As avaliações em larga escala foram instituídas dentro da mesma dinâmica que engendra a gestão e as reformas na educação. Estabelecer uma cultura da avaliação foi o objetivo iniciado com a criação do Sistema Nacional da Avaliação que, na época, foi uma exigência externa. Ao longo das últimas décadas, houve um aprofundamento das políticas de avaliação, como maneira de regular o currículo 
através do discurso da qualidade do sistema educacional. Entretanto, a avaliação tem servido mais como mecanismo de controle e de ranqueamento entre escolas e instituições, do que propriamente como uma indutora da qualidade.

Diante desse cenário, podemos perceber que a gestão democrática, pela qual muitas lutas foram desenvolvidas ao longo da história da educação brasileira na república, é fragilizada, com a introdução do ideário neoliberal e gerencialista, que desvirtua o princípio da participação coletiva da comunidade escolar, com a introdução das funções de responsabilização, sobretudo em relação aos professores.

Acreditamos que a gestão escolar é importante elemento de garantia da educação como direito universal e fator de justiça social, por isso seu lugar precisa ser recuperado e reposicionado nas políticas educacionais.

\section{REFERENNCIAS}

ALTVATER, Elmar. O fim do capitalismo tal qual o conhecemos. Rio de Janeiro: Civilização Brasileira, 2010.

ANADON, Simone Barreto; GARCIA, Maria Manuela Alves Garcia. "Educar para crescer" ou auditar para crescer? Governando para o desenvolvimento. Ensaio: aval. pol. públ. Educ., Rio de Janeiro, v. 23, n. 87, p. 341-365, abr./ jun. 2015.

BALL, Stephen J.; BOWE, Richard. Subject departments and the "implementation" of National Curriculum policy: an overview of the issues. Journal of Curriculum Studies, London, v. 24, n. 2, p. 97-115, 1992.

BALL, S.J. What is policy? Texts, trajectories and toolboxes. Discourse, London, v. 13, n. 2, p. 10-17, 1993.

BALL, Stephen J. Intelectuais ou técnicos? O papel indispensável da teoria nos estudos educacionais. In: BALL, Stephen J; MAINARDES, Jefferson (Orgs.) Políticas Educacionais: questões e dilemas. São Paulo: Editora Cortez, 2011.

BALL, Stephen J. What is policy? 21 years later: reflections on the possibilities of policy research. Discourse, Studies in the Cultural Politics of Education, v. 36, n. 3, 2015. Disponível em: http://dx.doi.org/10.1080/01596306.2015.10152 79. Acesso em: 10 abr. 2021. 
BALL, Stephen J. et al. A constituição da subjetividade docente no Brasil: um contexto global. Revista Educação em Questão, Natal, v. 46 n. 32, p. 9-36, maio/ago. 2013.

BRASIL. SAE. Pátria educadora: a qualificação do ensino básico como obra de construção nacional, 2015. Disponível em: http://pne.mec.gov.br/images/pdf/ Noticias/Patria_Educadora_documento_preliminar_SAE.pdf. Acesso em: 23 de maio de 2018.

BRUNS, Barbara; FILMER, Deon; PATRINOS, Harry Anthony. Making Schools Work: New evidence on accountability reforms. Overviewbooklet. Washington, D.C.: Banco Mundial, 2011.

BRUNS, Barbara; LUQUE, Javier. Professores excelentes: como melhorar a aprendizagem dos estudantes na América Latina e Caribe. Overviewbooklet. Washington, D.C.: Banco Mundial, 2014.

FOUCAULT, Michel. The archaeology of knowledge. London: Tavistock, 1977.

GIFE. Fundação Victor Civita lança livro Estudos \& Pesquisas Educacionais. Disponível em: https://gife.org.br/fundacao-victor-civita-lancalivro-estudos-pesquisas-educacionais/. Acesso em: 25 de jul. 2018.

HYPOLITO, Álvaro Moreira. Trabalho docente e o novo Plano Nacional de Educação: valorização, formação e condições de trabalho. Caderno Cedes, Campinas, v. 35, n. 97, p. 517-534, set./dez., 2015.

MAINARDES, Jefferson. Abordagem do ciclo de politicas: uma contribuição para a análise de políticas educacionais. Educação e Sociedade, Campinas, v. 27, n. 94, p. 47- 69, jan./abr. 2006.

SAUL, Renato P. As raízes renegadas da teoria do capital humano. Revista Sociologia, Porto Alegre, ano 6, nº 12, pp. 230-273, jul./dez., 2004.

SCHULTZ, Theodore W. O valor econômico da educação. Trad. P. S. Werneck. Rio de Janeiro: Zahar Editores, 1967. 
SHIROMA, Eneida Oto; GARCIA, Rosalba Maria Cardoso; CAMPOS, Roselane de Fátima. Conversão das "almas" pela liturgia da palavra: uma análise do discurso do movimento Todos pela Educação. In: BALL, Stephen J; MAINARDES, Jefferson (Orgs.) Políticas Educacionais: questões e dilemas. São Paulo: Editora Cortez, 2011.

STRASBURG, Quênia Renee. Banco Mundial: análise da trajetória de influências nas políticas educacionais. In: CORSETTI, Berenice; FONTOURA, Julian; ECOTEN, Márcia. (Orgs.). Políticas educacionais: contextos e análises contemporâneas. São Leopoldo: Casa Leiria, v. 1, p. 113-134, 2019.

VIEIRA, Fabiana Padovan. O papel(ão) da mídia na sociedade. 2010. Disponível em: http://observatoriodaimprensa.com.br/feitos-desfeitas/opapelao-da-midia-na-sociedade/. Acesso em: 10 jul.2020.

\section{Quênia Renee Strasburg}

Possui Bacharelado em Teologia pela Escola Superior de Teologia, Licenciatura em História pela Universidade Luterana do Brasil, Mestrado e Doutorado em Educação pela Universidade do Vale do Rio dos Sinos, professora da Rede Municipal de Educação de São Leopoldo/RS. E-mail: qrstras@gmail.com

\section{Berenice Corsetti}

Possui Graduação em História pela Universidade de Caxias do Sul, Mestrado em História pela Universidade Federal Fluminense, Doutorado e Pós-Doutorado em Educação pela Universidade Estadual de Campinas. É bolsista Produtividade em Pesquisa 1D do CNPq e professora titular da Universidade do Vale do Rio dos Sinos, vinculada ao Programa de Pós-Graduação em Educação. Desenvolve investigações em temáticas relacionadas à História da Educação e às Políticas Educacionais. E-mail: bcorsetti@unisinos.br 